\section{() OPEN ACCESS}

\title{
Content analysis of clinical questions from Australian general practice which are prioritised for answering: identifying common question types and perceived knowledge gaps
}

\section{Danielle Marie Muscat (1) ,,2 Pinika Patel, ${ }^{2}$ Sharon Reid, ${ }^{2}$ Tammy Hoffmann, ${ }^{3}$ Loai Albarqouni, ${ }^{3}$ Lyndal Trevena ${ }^{2}$}

\subsection{6/bmjebm-2019-111210}

\begin{abstract}
${ }^{1}$ Sydney Health Literacy Lab, School of Public Health, Faculty of Medicine and Health, University of Sydney, Sydney, New South Wales, Australia

${ }^{2}$ ASK-GP Centre for Research Excellence, School of Public Health, Faculty of Medicine and Health, University of Sydney, Sydney, New South Wales, Australia ${ }^{3}$ ASK-GP Centre for Research Excellence, Centre for Research in Evidence-Based Practice, Bond University, Gold Coast, Queensland, Australia
\end{abstract}

Correspondence to: Lyndal Trevena, ASKGP Centre for Research Excellence, School of Public Health, Faculty of Medicine and Health, University of Sydney, Sydney New South Wales Australia ; lyndal. trevena@sydney.edu.au

\section{Check for updates}

(- Author(s) (or their employer(s)) 2020. Re-use permitted under CC BY-NC. No commercial re-use. See rights and permissions. Published by BMJ.

To cite: Muscat DM,

Patel P, Reid S, et al. BMJ

Evidence-Based Medicine 2020;25:15-21.

\section{Abstract}

Perceived knowledge gaps in general practice are not well documented but must be understood to ensure relevant and timely evidence for busy general practitioners (GPs) which reflects their diverse and changing needs. The aim of this study was to classify the types of questions submitted by Australian GPs to an evidence-based practice information service using established and inductive coding systems. We analysed 126 clinical questions submitted by 53 Australian GPs over a 1.5-year period. Questions were coded using the International Classification of Primary Care (ICPC2 PLUS) and Ely and colleagues' generic questions taxonomy by two independent coders. Inductive qualitative content analysis was also used to identify perceived knowledge gaps. Treatment (71\%), diagnosis (15\%) and epidemiology (9\%) were the most common categories of questions. Using the ICPC-2 classification, questions were most commonly coded to the endocrine/metabolic and nutritional chapter heading, followed by general and unspecified, digestive and musculoskeletal. Seventy per cent of all questions related to the need to stay up-to-date with the evidence, or be informed about new tests or treatments (including complementary and alternative therapies). These findings suggest that current guideline formats for common clinical problems may not meet the knowledge demands of GPs and there is gap in access to evidence updates on new tests, treatments and complementary and alternative therapies. Better systems for 'pulling' real-time questions from GPs could better inform the 'push' of more relevant and timely evidence for use in the clinical encounter.

\section{Introduction}

A major challenge facing health professionals is the need to ensure that personal clinical knowledge is up-to-date to support effective patient care. This challenge is exacerbated by the evergrowing mass of clinical guidelines and available evidence, ${ }^{1}$ and further intensified in general practice given the broad role of clinicians in this setting. Not surprisingly, clinical questions at the point of care are common. ${ }^{2}$ Understanding the nature of clinical questions can help to ensure relevant and timely evidence for general practitioners (GPs); rather than 'pushing' evidence to GPs through disease-based guidelines, the information needs of clinicians can be used to drive the development of guidelines and resources that are relevant to their practice.

A 2014 systematic review of questions raised by clinicians (physicians, medical residents, physician assistants, nurse practitioners, nurses, dentists and care managers) at the point of care identified 64 studies which classified clinical questions. ${ }^{2}$ The majority (75\%) of included studies used ad hoc and informal classification approaches with poorly defined categories and methods, resulting in substantial variability between studies and precluding meaningful comparisons across time and geographical contexts. ${ }^{2}$ Five studies classified questions according to a formal taxonomy developed by Ely and colleagues ${ }^{3}$ and found that 34\% of the questions asked were about drug treatments, and $24 \%$ were related to the potential causes of a symptom, physical finding or diagnostic test finding. Ely and colleagues' ${ }^{3}$ taxonomy is useful in providing an overview and comparison of the general nature of questions asked in clinical practice. However, as it is deliberately generic, it does not allow for a detailed exploration of the conditions, treatments or tests of interest to clinicians which may be more subject to change over time. In this way, its use may need to be complemented by other classification approaches.

Only three of the studies which classified clinical questions included in the systematic review ${ }^{2}$ were conducted in Australian settings, ${ }^{4-6}$ with the most recent article published over 10 years ago. Given that there have been major changes in Australian general practice over time including changes in GP and practice characteristics, reasons for encounters, problems managed and the management provided, ${ }^{7}$ clinical questions may have also changed over time. In addition, none of the 26 studies from the systematic review which analysed questions submitted to an information service used Ely's taxonomy. This limits the comparisons which can be made between clinical questions simply arising from practice (without further action taken) and those which are prioritised for answering after the consultation. Given that clinicians pursue roughly half of their clinical questions ${ }^{2}$ and often do not pursue questions 
because they do not perceive them to be urgent or important, ${ }^{2}$ understanding the nature of those questions which are prioritised is a necessary step in facilitating evidence-based practice (EBP).

Evidence-based information services are a way of supporting clinicians to answer their clinical questions, and seek to overcome some of the perceived barriers to EBP (see Sadeghi-Bazargani et $a l,{ }^{8}$ for an overview of barriers). Throughout 2017, we piloted an information service embedded within an EBP journal club $^{9}$ in general practices in New South Wales and Queensland, Australia. This was part of a larger programme of work to support EBP and shared decision-making in general practice, and extends on previous efforts developing and evaluating 'literature searching services' for GPs. ${ }^{6}$ Five GP practices in New South Wales and Queensland were invited to participate in the information service, and to formulate and submit clinical questions arising from daily practice that they felt warranted answering and further discussion/critical appraisal in a subsequent journal club. These practices were purposively selected as early adopters of clinical advances and for comprising opinion leaders likely to influence national change. The aims of this study were to investigate the types of questions submitted by participating practices and characterise GPs' information needs by classifying their questions using established and inductive coding systems.

\section{Methods}

In this study, we analysed clinical questions submitted by GPs participating in our information service and EBP journal club over the period of 1.5 years (between June 2016 and December 2017). Participating general practices submitted questions from clinical practice to the information service via an email from an assigned GP liaison. Questions were stored in an internal database and retrieved for coding in January 2018. Deductive and inductive coding methods were used to classify questions.

\section{Deductive coding: question type ICPC-2 PLUS}

The International Classification of Primary Care (ICPC) is a classification system for general practice. The first version (ICPC V.1) ${ }^{10}$ was published in 1987 with the second (ICPC-2) published by the World Organization of Family Doctors in 1997. ${ }^{11}$ ICPC-2 is accepted by the WHO in the WHO Family of International Classifications, and is the declared national standard in Australia for reporting of health data from general practice and patient selfreported health information. ${ }^{7}$ ICPC-2 PLUS is a clinical terminology and online interface classified to ICPC-2 and was used in this study. ${ }^{12}$

ICPC-2 is a multilevel coding system with 17 chapters: general (A), blood/blood forming (B), digestive (D), eye (F), ear (H), circulatory (K), musculoskeletal (L), neurological (N), psychological $(\mathrm{P})$, respiratory $(\mathrm{R})$, skin $(\mathrm{S})$, metabolic/endocrine/nutritional $(\mathrm{T})$, urinary (U), pregnancy/family planning (W), female genital (X), male genital $(\mathrm{Y})$ and social $(\mathrm{Z})$. Health data can also be classified with more granularity using ICPC-2 clinical terms. Examples of domains the terms may include are a disease label (eg, hypertension), a symptom (eg, cough) or a procedure (eg, dressing). ${ }^{12}$

\section{Taxonomy of generic clinical questions}

Previous research by Ely and colleagues ${ }^{3}$ and Ebell and White ${ }^{13}$ developed and validated a taxonomy of generic clinical questions that classifies clinical questions into 1 of 64 generic types (eg, What is the cause of symptom $\mathrm{x}$ ?; How good is test $\mathrm{x}$ in situation y?). Question types are broadly categorised as: diagnosis, treatment, management, epidemiology, non-clinical and nonclassified.

\section{Analysis}

ICPC-2 PLUS was used by two blinded independent coders (DMM and PP), to code each clinical question at the level of chapters and clinical terms. If more than one chapter heading or clinical term could be applied to the question, all applicable were documented. Any conflicts and discrepancies in coding were resolved by a third coder with extensive clinical experience in general practice (LT).

All clinical questions were also assigned a category from the taxonomy of generic clinical questions by LT and SR, with any discrepancies resolved through discussion. If more than one category could be applied to the question, all applicable were documented.

\section{Inductive coding: perceived knowledge gaps}

In addition to coding the questions deductively based on ICPC-2 PLUS and the taxonomy of generic clinical questions, we conducted a qualitative content analysis of questions to identify perceived knowledge gaps. Coding was performed inductively with categories derived from the data. ${ }^{14}$ Inductive codes were collected by senior author (LT) to form coding sheets and categories freely generated and grouped through the abstraction process. ${ }^{14}$ The coding scheme was revised over a two-round iterative process of discussion and revision involving LT and DMM. Two coders (LT and SR) then independently applied the final coding scheme to the full list of questions. Discrepancies were resolved by discussion between LT and SR.

\section{Results}

\section{Demographic data}

The five participating general practice groups had a total of 53 GP members. The number of years practicing per GP ranged from 1 to 43 years. All practices were classified as 'urban' on the basis of population ranges according to the Section of State Structure of the Australian Statistical Geography Standard. ${ }^{15}$ One practice was a university health service.

\section{Description of the database}

A total of 126 questions from the five participating practice groups were entered into the database over the period of 1.5 years (June 2016 to December 2017). The number of questions submitted per practice per month varied, with a range of 0-10 questions.

\section{ICPC-2 PLUS}

ICPC-2 chapter headings and clinical terms for coded questions are presented in table 1 . Nine clinical questions were not able to be coded using ICPC-2 PLUS and hence were not included (eg, What are patient views and emotional reactions to health professionals looking up resources during consultations?). Of those that were coded, 20 questions fell under two of the chapter headings, and one fell under three chapter headings. Regarding clinical terms, 38 questions fell under two of clinical terms, and 11 fell under three or more.

Aside from the 'general and unspecified' chapter heading, the highest number of questions was coded to the 'endocrine/metabolic and nutritional' ICPC-2 chapter heading ( $\mathrm{n}=19 ; 13.7 \%)$, followed by the 'musculoskeletal' chapter heading $(n=16 ; 11.5 \%)$. Overall, the most common clinical terms were non-insulindependent diabetes (4\%), blood test (endocrine/metabolic and nutritional (3\%)); general and unspecified (3\%)), and osteoporosis 
Table 1 Number of questions under each chapter heading from the ICPC-2 PLUS classification system

\begin{tabular}{|c|c|c|c|}
\hline ICPC-2 PLUS chapter heading & $\mathrm{n}(\%)$ & ICPC-2 PLUS terms & n (\%) \\
\hline Endocrine/metabolic and nutritional & $19(13.7)$ & $\begin{array}{l}\text { Limited function/disability (t); endocrine/met/sympt/complt other; blood } \\
\text { test; observe/educate/advice/diet; therapeutic counselling/listening; } \\
\text { other referrals NEC; obesity; hypothyroidism/myxoedema; diabetes insulin } \\
\text { dependent; diabetes non-insulin dependent; gout; endocrine/metab/nutrit. } \\
\text { disorder other }\end{array}$ & $30(16.5)$ \\
\hline General and unspecified & $19(13.7)$ & $\begin{array}{l}\text { Weakness/tiredness general; limited function/disability NOS; microbiological/ } \\
\text { immunological test; blood test; urine test; other diagnostic procedure; } \\
\text { diagnostic endoscopy; diagnostic radiology/imaging; preventive } \\
\text { immunisation/medication; infectious disease other/NOS; malignancy NOS; } \\
\text { complication of medical treatment; abnormal result investigation NOS; allergy/ } \\
\text { allergic reaction NOS }\end{array}$ & $25(13.7)$ \\
\hline
\end{tabular}

\begin{tabular}{|c|c|c|c|}
\hline Musculoskeletal & $16(11.5)$ & $\begin{array}{l}\text { Back symptom/complaint; muscle pain; sympt/comply. Musculoskeletal } \\
\text { other; diagnostic radiology/imaging; consult with primary care provider; } \\
\text { Medicat-script/Reqst/Renew/Inject; local injection/infiltration; infections } \\
\text { musculoskeletal system; fracture: other; back syndrome with radiating pain; } \\
\text { bursitis/tendinitis/synovitis NOS; osteoarthritis of knee; osteoarthritis other; } \\
\text { shoulder syndrome; osteoporosis }\end{array}$ & $21(11.5)$ \\
\hline Digestive & $12(8.6)$ & $\begin{array}{l}\text { Abdominal pain/cramps general; dyspepsia/indigestion; flatulence/gas/ } \\
\text { belching; diarrhoea; rectal bleeding; digestive microbiological/immunological } \\
\text { test; faeces test; diagnostic endoscopy (colonoscopy); gastrointestinal } \\
\text { infection; congen. Anomaly digestive system; oesophagus disease; irritable } \\
\text { bowel syndrome; chronic enteritis/ulcerative colitis; disease digestive system, }\end{array}$ & $21(11.5)$ \\
\hline
\end{tabular}
other

\begin{tabular}{|c|c|c|c|}
\hline Psychological & $12(8.6)$ & $\begin{array}{l}\text { Sleep disturbances; memory disturbances; specific learning problems; } \\
\text { psychological symptom/complt other; dementia; affective psychosis; } \\
\text { depressive disorder; psychological disorders, other }\end{array}$ & $15(8.2)$ \\
\hline Cardiovascular & $12(8.6)$ & $\begin{array}{l}\text { Medical examination/health evaluation-partial; physical function test; } \\
\text { diagnostic radiology/imaging; electrical tracings; cardiac arrhythmias NOS; } \\
\text { heart disease other; phlebitis/thrombophlebitis; cardiovascular disease other }\end{array}$ & $14(7.7)$ \\
\hline Skin & $12(8.6)$ & $\begin{array}{l}\text { Skin infection post-traumatic; excise/remove/biopsy/destruction/debride; } \\
\text { repair/fixate-suture/cast/prosthetic; other therapeutic procedure NEC; } \\
\text { malignant neoplasm of skin; solar keratosis/sunburn; psoriasis; acne }\end{array}$ & $14(7.7)$ \\
\hline Respiratory & $12(8.6)$ & $\begin{array}{l}\text { Cough; preventive immunisation/medications; influenza; pneumonia; } \\
\text { respiratory infection other; asthma }\end{array}$ & $12(6.6)$ \\
\hline Neurological & $8(5.8)$ & $\begin{array}{l}\text { Headache; speech disorder; migraine; cluster headache; peripheral neuritis/ } \\
\text { neuropathy }\end{array}$ & $9(4.9)$ \\
\hline Female genital & $7(5.0)$ & $\begin{array}{l}\text { Menopausal symptom/complaint; breast symptom/complaint. Female other; } \\
\text { malignant neoplasm breast female; fibromyoma uterus; abnormal cervix smear; } \\
\text { premenstrual tension syndrome }\end{array}$ & $6(3.3)$ \\
\hline $\begin{array}{l}\text { Pregnancy, childbearing, family } \\
\text { planning }\end{array}$ & $3(2.2)$ & $\begin{array}{l}\text { Question of pregnancy; blood test; diagnostic radiology/imaging; abortion } \\
\text { spontaneous; pregnancy high risk }\end{array}$ & $5(2.7)$ \\
\hline Male genital & $3(2.2)$ & Cystitis/urinary infection other; abnormal urine test NOS; urinary disease other & $4(2.2)$ \\
\hline $\begin{array}{l}\text { Blood, blood forming organs and } \\
\text { immune mechanism }\end{array}$ & $2(1.4)$ & $\begin{array}{l}\text { Breast symptom/complaint. Male; B medical examination/health evaluation- } \\
\text { partial; blood test }\end{array}$ & $4(2.2)$ \\
\hline Urological & $2(1.4)$ & Blood test & $2(1.1)$ \\
\hline Eye & $0(0)$ & N/A & $0(0)$ \\
\hline Ear & $0(0)$ & $\mathrm{N} / \mathrm{A}$ & $0(0)$ \\
\hline Social problems & $0(0)$ & $\mathrm{N} / \mathrm{A}$ & $0(0)$ \\
\hline Total & $139(100)$ & & $182(100)$ \\
\hline
\end{tabular}

ICPC, International Classification of Primary Care.

(3\%). There did not appear to be large variations in the question types between GP practice groups although this was not checked for statistical significance.

\section{Taxonomy of generic clinical questions}

Using the taxonomy of generic clinical questions, the majority of questions were related to the broad category of treatment (71.3\%), followed by diagnosis (14.5\%), epidemiology (9.2\%), management (2.3\%), non-clinical (0.8\%) and non-classified (0.8\%). More specific generic question types are shown in table 2 .

\section{Perceived knowledge gaps}

Eleven categories of perceived personal knowledge gaps were identified from the inductive abstraction process (see table 3).

\section{Discussion}

\section{Summary of findings}

This study of the types of questions submitted by 53 Australian GPs participating in an information service revealed that the majority of questions prioritised for answering by GPs related to treatment, followed by diagnosis and epidemiology, respectively. 
Table 2 Number of questions coded by question type from the taxonomy of generic clinical questions

\begin{tabular}{|c|c|c|c|}
\hline Code & Definition & $\mathrm{n}$ & $\%$ \\
\hline 2.1.2.1. & Is drug $\mathrm{x}$ (or drug class $\mathrm{x}$ ) indicated in situation $\mathrm{y}$ or for condition $\mathrm{y}$ ? & 28 & 21.7 \\
\hline 2.2.1.1. & How should I treat finding/condition y (given situation z)? & 23 & 17.8 \\
\hline 2.1.2.2. & Should this kind of patient get prophylactic drug $\mathrm{x}$ to prevent condition $\mathrm{y}$ ? & 15 & 11.6 \\
\hline 2.2.1.2. & Should this kind of patient get prophylactic treatment (intervention) $\mathrm{x}$ to prevent condition $\mathrm{y}$ ? & 11 & 8.5 \\
\hline 1.3.2.1. & How good is test $x$ in situation $y$ ? & 10 & 7.8 \\
\hline 4.2.1.1. & Is $\mathrm{x}$ a risk factor for condition $\mathrm{y}$ ? & 10 & 7.8 \\
\hline 2.1.1.3. & When (timing, not indication) or how should I start/stop drug $\mathrm{x}$ ? & 8 & 6.2 \\
\hline 1.3.1.1. & Is test $\mathrm{x}$ indicated in situation $\mathrm{y}$ ? & 7 & 5.4 \\
\hline 2.1.3.3. & Is drug $x$ safe to use in situation $y$ ? & 3 & 2.3 \\
\hline 3.1.1.1. & How should I manage condition/finding/situation y? & 2 & 1.6 \\
\hline 1.3.3.1. & When (timing, not indications) should I do test $x$ ? & 1 & 0.8 \\
\hline 1.7.1.1. & What is the cost of test $x ?$ & 1 & 0.8 \\
\hline 2.1.2.1. & Is drug $\mathrm{x}$ (or drug class $\mathrm{x}$ ) indicated in situation $\mathrm{y}$ or for condition $\mathrm{y}$ ? & 1 & 0.8 \\
\hline 2.1.3.1. & Could finding $y$ be caused by drug $x$ ? & 1 & 0.8 \\
\hline 2.1.3.2. & $\begin{array}{l}\text { How can drug } x \text { be administered without causing adverse effect } y \text { or minimising adverse effect } \\
y \text { or in spite of adverse effect } y \text { ? }\end{array}$ & 1 & 0.8 \\
\hline 2.1.4.1. & Is it $\mathrm{OK}$ to use drug $\mathrm{x}$ with drug $\mathrm{y}$ ? & 1 & 0.8 \\
\hline 2.2.1.1. & How should I treat finding/condition y (given situation z)? & 1 & 0.8 \\
\hline 3.2.2.1. & When should you refer in situation y? & 1 & 0.8 \\
\hline 4.3.1.1. & What is the usual course (or natural history) of condition y? & 1 & 0.8 \\
\hline 4.4.1.1. & Generic type varies (epidemiology not elsewhere classified) & 1 & 0.8 \\
\hline 5.1.1.3. & How can I better teach this trainee (medical student, resident, other provider)? & 1 & 0.8 \\
\hline 6.1.1.1. & Generic type varies. Unable to classify & 1 & 0.8 \\
\hline Total & & 129 & 100 \\
\hline
\end{tabular}

Using the ICPC-2 PLUS classification system, the most common chapter headings were 'endocrine/metabolic and nutritional' and 'general and unspecified', followed by 'musculoskeletal' and 'digestive'. Through an inductive coding process, we identified several knowledge gaps; however, over 70\% of all questions related to checking more specifically on one aspect of current evidence on a common problem, or to be informed about new tests or treatments and complementary and alternative therapies.

Several other studies have found questions concerning treatment to be the most common clinical question type. ${ }^{2516}$ This may be unsurprising given the role of the GP to "treat all common medical conditions', ${ }^{17}$ and patient expectations of (benefiting

Table 3 Perceived knowledge gaps, as identified through inductive coding

\begin{tabular}{|c|c|c|c|}
\hline & Category name & Example & $\mathrm{n}(\%)$ of questions \\
\hline 1 & $\begin{array}{l}\text { Checking more specifically on one aspect of current evidence } \\
\text { on a common problem (staying up-to-date-focused) }\end{array}$ & $\begin{array}{l}\text { Is there any evidence to support the recommendation to } \\
\text { avoid sex with a diagnosis of placenta praevia? }\end{array}$ & $34(27.0)$ \\
\hline 2 & $\begin{array}{l}\text { Checking claims/evidence about a relatively new test or } \\
\text { treatment }\end{array}$ & $\begin{array}{l}\text { Evidence for FMT (faecal matter transplant) in treating } \\
\text { ulcerative colitis }\end{array}$ & $22(17.5)$ \\
\hline 3 & Evidence for complementary and alternative therapies & Does fish oil prevent heart disease? & $22(17.5)$ \\
\hline 4 & $\begin{array}{l}\text { Checking broadly on guidelines and recommendations on a } \\
\text { common topic (staying up-to-date-broad) }\end{array}$ & Which migraine prophylaxis medication is most effective? & $13(10.3)$ \\
\hline 5 & $\begin{array}{l}\text { Application of evidence in a specific population subgroup or } \\
\text { setting }\end{array}$ & $\begin{array}{l}\text { What is the effectiveness of antiviral medications in } \\
\text { preventing complications in patients with influenza at low } \\
\text { and high risk of complications? }\end{array}$ & $13(10.3)$ \\
\hline 6 & $\begin{array}{l}\text { Evidence about stopping treatments (including safety and } \\
\text { minimising harms) }\end{array}$ & Do we need to stop metformin for patients with diabetes? & $7(5.6)$ \\
\hline 7 & Evidence for practice processes & $\begin{array}{l}\text { What are patients' views and emotional reactions to health } \\
\text { professionals looking up resources during consultations? }\end{array}$ & $5(4.0)$ \\
\hline 8 & Checking on the safety or harms of a test or treatment & Adverse effects of proton pump inhibitors & $4(3.2)$ \\
\hline 9 & Evidence about lifestyle choices & Does exercise reduce the risk of cancer? & $3(2.4)$ \\
\hline 10 & Education (eg, clinical teaching, learning EBM skills) & $\begin{array}{l}\text { What personal qualities and behaviours do patients, } \\
\text { medical students and trainees/registrars highly rate in } \\
\text { their GP or their GP supervisor? }\end{array}$ & $2(1.6)$ \\
\hline \multirow[t]{2}{*}{11} & Checking the evidence about a less frequent condition & Surgery versus other treatments for trigger thumb & $1(0.8)$ \\
\hline & Total & & 125 (100\%) \\
\hline
\end{tabular}

GP, general practitioner. 
from) treatment. ${ }^{18} 19$ However, the percentage of questions pertaining to treatment was higher in our study compared with other Australian studies published $11(35 \%)^{5}$ and 18 years ago $(65 \%){ }^{6}$ This may be an artefact of slightly different classification systems across studies. For example, the taxonomy of generic clinical questions does not include a separate 'prevention' category, so may not reflect the expanding role of GPs in preventive healthcare activities. These include promoting smoking cessation, responsible alcohol consumption, weight control, physical activity and undertaking screening activities including blood pressure monitoring, cholesterol and blood glucose measurement and cancer screening. As well as generic question types, there are also some similarities between our findings regarding ICPC-2 PLUS classifications and other studies. Magrabi and colleagues, for example, found that gastrointestinal (13\%), skin (12\%) and musculoskeletal (11\%) were the top three disease categories in a study of clinical questions from 227 Australian GPs, ${ }^{4}$ corresponding with two of three of our most common ICPC-2 PLUS chapter headings, and a study of questions submitted to a popular GP-restricted (Australia, New Zealand) Facebook group ${ }^{16}$ had two of the five major clinical topics (musculoskeletal and psychology) from our study. Future research may benefit from additional triangulation of data from different sources (eg, encounter observations; questions submitted to EBP question-answering services; questions submitted to public forums) to explore the role of different networks in answering clinical questions and to identify the most common question types across all forums.

Through the use of a standard classification system (ICPC-2 PLUS), our results can also be compared with findings from the Bettering the Evaluation of Care and Health (BEACH) programme; a continuous 18-year national study of general practice activity in Australia. ${ }^{7}$ BEACH data from 2006-2007 to 2015-2016 indicates that general and unspecified problems were the most frequently managed type of problem in 2015-2016; their management rate increased from 16.2 per 100 encounters in 2006-2007 to 20.0 per 100 in 2015-2016, an increase of 23.5\% over the decade. ${ }^{7}$ There were also substantial increases in the management rates of endocrine and metabolic problems in general practice encounters between 2006-2007 and 2015-2016, from 12.1 to 13.5 per 100 encounters. ${ }^{7}$ In all years from 2006-2007 to 2015-2016, the five most commonly managed problems were hypertension, immunisation, upper respiratory tract infection, depression and diabetes. ${ }^{20}$ These mirror our findings and highlight that GP's clinical questions overlap with the common problems they see in practice. Similarly, the categories for which we did not code any questions (eg, ear, eye and social problems) were in the six least common reasons for an encounter by ICPC-2 chapter, accounting for 3.2\%, $1.9 \%$ and $1.0 \%$ of clinical questions from 2015 to $2016 \mathrm{BEACH}$ data. ${ }^{7}$

A novel contribution of this study is the use of inductive coding of GPs' questions to identify perceived knowledge gaps. The need to stay up-to-date with the state of evidence and be informed about new tests or treatments were the most prevalent knowledge gaps. Other studies have similarly identified the need to achieve basic 'currency' as a driver of clinical questions. ${ }^{21}$ Based on our inductive coding scheme, staying up-to-date included checking broadly on guidelines and recommendations for a common topic $(10 \%)$ as well as checking in a more focused 'specific' way on one aspect of current evidence for a common problem (27\%). Aligned with this, Brassil and colleagues found that more than half of the respondents stated that their clinical questions arose from 'unusual cases. ${ }^{22}$ This reinforces that even though GPs often manage common problems, focused questions about specific nuisances of a problem remain an important knowledge gap. In addition to achieving currency, $18 \%$ of questions in this study were coded as knowledge gaps about complementary and alternative therapies/medicines (CAM). CAM is estimated to be used by up to two out of three Australians, ${ }^{23}$ and other studies have likewise found a perceived lack of knowledge about complementary and alternative therapies among Australian GPs. ${ }^{24}$ In a study to assess questions about CAM to the Regional Medicines Information and Pharmacovigilance Centres in Norway, Schjott and Erdak found that 7.7\% of all questions regarded CAM. ${ }^{25}$ Together, these findings highlight the growing prevalence of questions about CAM from mainstream clinical practice and the knowledge gaps which remain in this area.

\section{Directions for research and practice}

Our results highlight that GPs' clinical questions frequently relate to treatment and to commonly managed problems, but are often focused more narrowly on specific aspects of a problem or new tests and treatments. The submission of such questions to our information service suggests that some GPs may not feel wellequipped to manage some of the diverse nuances of common presentations. In line with this, previous studies have found that published research and clinical guidelines do not align with the problems most frequently encountered by $\mathrm{GPs}^{21}$ and continuing professional development programmes do not always correlate well with the spectrum of common clinical issues experienced on a daily basis by clinicians. ${ }^{26}$

In Australia, the National Health and Medical Council recognises that, if guidelines are to be relevant, those who are expected to use them should play a part in their conception. ${ }^{27}$ However, there are currently no system-wide approaches for obtaining GPs' evidence and knowledge gaps, and clinical practice guidelines are often commissioned by different groups in a top-down manner (eg, based on government health priority topics). Our system for 'pulling' real-time questions from GPs may help to circumvent this, and can inform the 'push' of more relevant and timely evidence for use in the clinical encounter. Other work has also shown that sustained relationships between clinical practices and academic groups can help to raise and answer clinical questions of importance to GPs. ${ }^{28}$ To ensure sustainability of this method to 'pull' clinical questions into evidence ecosystems, work is needed to support linkages between academic departments, general practices and guideline developers, as well as sustained and sufficient funding for infrastructure including staff. ${ }^{29}$

Our results also support the increasing advocacy for "living guidelines. ${ }^{30}$ A living guideline is one that remains under review on an ongoing basis, with updates published at set intervals (eg, annually). ${ }^{25}$ The use of living guidelines can support clinicians to find evidence about new tests and treatments more easily and, if hosted on searchable digital platforms, may better support them to search for specific information about aspects of a problem. ${ }^{30}$ This represents an important advance on the lengthy, static clinical practice guidelines currently in use throughout Australia. Finally, our findings also reinforce the call for better awareness and resources about CAM. Even where there is limited or uncertain evidence for CAM, this should be included in clinical guidelines to ensure that clinicians are informed about the evidence and can communicate this to patients to support informed, shared decision-making. This may help to increase the number of people who consult their GP prior to using CAM (currently only 20\% in Australia ${ }^{31}$ ) and is particularly important given the competing sources (social networks; books; media; internet ${ }^{31}$ ) and quality of information available to patients. 


\section{Strengths and limitations}

We analysed questions from a small and non-randomly selected sample of GPs, which limits the generalisability of our findings. In fact, we purposively selected lead practices recognised as opinion leaders and early adopters of clinical advances. The fact that even these lead GPs had clinical questions which they requested assistance in answering supports the utility of, and need for, better systems for pulling real-time questions from GPs to guide research and the development and revision of practice guidelines. As all questions were submitted via an appointed GP liaison, we do not have information about which GP submitted each question, so some GPs may be over-represented in the database, and it is possible that the GPs actually contributing questions may be the most motivated and evidence-aware practitioners within those practices.

Direct observation studies such as that of Ely et $a l^{3}$ have shown that GPs generate 10-15 questions per day of practice. We, therefore, received a very select number of questions from participating GPs which is unlikely to be representative of the much larger number of questions that they generate. However, this study was designed to investigate the types of questions that GPs at the practice level have prioritised for answering to improve the quality of

Key messages

What is already known about this subject?

- Clinical questions at the point of care are common; however, clinicians only pursue roughly half of these questions.

- Evidence-based information services are a way of supporting clinicians to answer prioritised clinical questions, and seek to overcome some of the perceived barriers to evidence-based practice.

\section{What are the new findings?}

- Treatment (71\%), diagnosis (15\%) and epidemiology ( $9 \%$ ) were the most common categories of questions submitted to a journal club support service by 53 Australian general practitioners (GPs) over a 1.5-year period.

- Using the International Classification of Primary Care 2 classification, the highest number of questions was coded to the endocrine/metabolic and nutritional chapter heading, followed by general and unspecified, digestive and musculoskeletal.

- Seventy per cent of all questions related to the need to stay up-to-date with the evidence, or be informed about new tests or treatments (including complementary and alternative therapies).

- Clinical questions prioritised for answering by Australian GPs overlapped with common clinical presentations.

\section{How might it impact on clinical practice in the foreseeable future?}

- Understanding the nature of clinical questions prioritised for answering can help to target research and resources towards meeting GPs' specific information needs.

- Methods and findings can support better systems for 'pulling' real-time questions from GPs to inform the 'push' of more relevant and timely evidence for use in the clinical encounter. practice and uptake of evidence. The questions submitted to our service may also reflect those which GPs have particular difficulty answering through other means.

The use of multiple coding systems and independent coders are strengths of our study. Standard classification systems such as ICPC-2 plus allow for meaningful comparison of clinical questions over time and contexts. The ICPC- 2 is now used in $>45$ countries as the standard for data classification in primary care, ${ }^{7}$ which also allows us to compare clinical questions to clinical presentations. We coded all questions submitted by GP groups, not only those which were answered by our information service.

\section{Conclusion}

This study investigated the types of questions submitted by Australian GP groups over a period of 1.5 years and characterised GPs' information needs by classifying their questions using established and inductive coding systems. Our findings highlight the diverse range of clinical questions which arise in general practice, but show that topic areas often overlap with common clinical presentations and often concern treatment. The questions submitted reinforce GPs' need to stay up-to-date and desire to know more about the evidence for complementary and alternative medicines. Going forward, it is necessary to target research and resources towards meeting GPs' specific information needs to support the dissemination of relevant and timely evidence for use in clinical encounters. .

Acknowledgements Thanks to all of the GPs who participated in this study and contributed clinical questions.

Contributors LT, DMM, TH and PP conceived of this study and its design, and were responsible for data collection. LT, DMM, PP and SR performed the content analysis and coding, and all authors were involved in interpreting the results. All authors discussed the results and commented on the manuscript.

Funding This project was funded by a National Health and Medical Research Council Centre for Research Excellence (ID: 1106452).

Competing interests None declared.

Patient consent for publication Not required.

Ethics approval The study was approved by the University of Sydney Human Research Ethics Committee (Protocol \# 2016/1011).

Provenance and peer review Not commissioned; externally peer reviewed.

Open access This is an open access article distributed in accordance with the Creative Commons Attribution Non Commercial (CC BY-NC 4.0) license, which permits others to distribute, remix, adapt, build upon this work non-commercially, and license their derivative works on different terms, provided the original work is properly cited, appropriate credit is given, any changes made indicated, and the use is non-commercial. See: http://creativecommons.org/licenses/by-nc/4.0/.

\section{ORCID iD}

Danielle Marie Muscat http://orcid.org/0000-0001-6106-6298

\section{References}

1. Bastian H, Glasziou P, Chalmers I. Seventy-five trials and eleven systematic reviews a day: how will we ever keep up? PLoS Med 2010;7:e1000326. 
2. Del Fiol G, Workman TE, Gorman PN. Clinical questions raised by clinicians at the point of care: a systematic review. JAMA Intern Med 2014;174:710-8.

3. Ely JW, Osheroff JA, Ebell MH, et al. Analysis of questions asked by family doctors regarding patient care. BMJ 1999;319:358-61.

4. Magrabi F, Coiera EW, Westbrook JI, et al. General practitioners' use of online evidence during consultations. Int J Med Inform 2005;74:1-12.

5. Magrabi F, Westbrook JI, Kidd MR, et al. Long-term patterns of online evidence retrieval use in general practice: a 12-month study. J Med Internet Res 2008;10:e6.

6. Del Mar CB, Silagy CA, Glasziou PP, et al. Feasibility of an evidencebased literature search service for general practitioners. Med J Aust 2001;175:134-7.

7. Britt H, Miller GC, Bayram C, et al. A decade of Australian general practice activity 2006-07 to 2015-16. Sydney, Australia: Sydney University Press 2016.

8. Sadeghi-Bazargani H, Tabrizi JS, Azami-Aghdash S. Barriers to evidencebased medicine: a systematic review. J Eval Clin Pract 2014;20:793-802.

9. Doust J, Del Mar CB, Montgomery BD, et al. EBM journal clubs in general practice. Aust Fam Physician 2008;37:54-6.

10. International Classification of Primary Care. Oxford, UK: Oxford University Press, 1987.

11. World Organisation of Family Doctors (WONCA). ICPC-2: International Classification of Primary Care Oxford. UK: Oxford University Press, 1997.

12. Australian Institute of Health and Welfare (AIHW). International Classification of Primary Care, Second edition PLUS. 2016 http://meteor. aihw.gov.au/content/index.phtml/itemId/596654 (accessed 23 Oct 2018).

13. Ebell MH, White L. What is the best way to gather clinical questions from physicians? J Med Libr Assoc 2003;91:364-6.

14. Elo S, Kyngäs $\mathrm{H}$. The qualitative content analysis process. $J$ Adv Nurs 2008;62:107-15.

15. Australian Bureau of Statistics. Australian Statistical Geography Standard (ASGS). http://www.abs.gov.au/websitedbs/D3310114.nsf/home/Australian+ Statistical+Geography+Standard+(ASGS) (accessed 27 July 2018).

16. Albarqouni L, Hoffmann T, McLean K, et al. Role of professional networks on social media in addressing clinical questions at general practice: a cross-sectional study of general practitioners in Australia and New Zealand. BMC Fam Pract 2019;20:1-6 https://doi.org/.

17. England HE, Practice G. GP). Website https://www.healthcareers.nhs.uk/ explore-roles/doctors/roles-doctors/general-practice-gp (Accessed 29 July 2018).

18. Hoffmann TC, Del Mar C. Patients' expectations of the benefits and harms of treatments, screening, and tests: a systematic review. JAMA Intern Med 2015;175:274-86.
19. Pathirana T, Clark J, Moynihan R. Mapping the drivers of overdiagnosis to potential solutions. BMJ 2017;358:3879.

20. Cooke G, Valenti L, Glasziou P, et al. Common general practice presentations and publication frequency. Aust Fam Physician 2013;42:65-8.

21. Magin P, Tapley A, Davey A, et al. General practitioner trainees' in-consultation generation of clinical questions for later answering: prevalence and associations. Fam Pract 2017;34:599-605.

22. Brassil E, Gunn B, Shenoy AM, et al. Unanswered clinical questions: a survey of specialists and primary care providers. J Med Libr Assoc 2017;105:4-11.

23. Xue CC, Zhang AL, Lin V, et al. Complementary and alternative medicine use in Australia: a national population-based survey. J Altern Complement Med 2007;13:643-50.

24. Janamian T, O'Rourke P, Myers SP, et al. Information resource needs and preference of queensland general practitioners on complementary medicines: result of a needs assessment. Evid Based Complement Alternat Med 2011;2011:1-6.

25. Schjøtt J, Erdal H. Questions about complementary and alternative medicine to the Regional Medicines Information and Pharmacovigilance Centres in Norway (RELIS): a descriptive pilot study. BMC Complement Altern Med 2014;14:56

26. Archibald D, Liddy C, Lochnan HA, et al. Using Clinical Questions Asked by Primary Care Providers Through eConsults to Inform Continuing Professional Development. J Contin Educ Health Prof 2018;38:41-8.

27. National Health and Medical Research Council (NHMRC). A guide to the development, implementation and evaluation of clinical practice guidelines. Canberra, ACT: AusInfo, 1998.

28. Heal C, Buettner P, Raasch B, et al. Can sutures get wet? Prospective randomised controlled trial of wound management in general practice. BMJ 2006;332:1053-6.

29. Pirotta M, Temple-Smith M. Practice-based research networks. Aust Fam Physician 2017;46:793-5.

30. Kaiser K, Miksch S. Versioning computer-interpretable guidelines: semiautomatic modeling of 'Living Guidelines' using an information extraction method. Artif Intell Med 2009;46:55-66.

31. Murthy V, Adams J, Broom A, et al. The influence of communication and information sources upon decision-making around complementary and alternative medicine use for back pain among Australian women aged 6065 years. Health Soc Care Community 2017;25:114-22. 